p-ISSN. 2086-9029

e-ISSN. 2654-5675

Vol. 21 No. 1, HIm. 1-124, Juni 2019

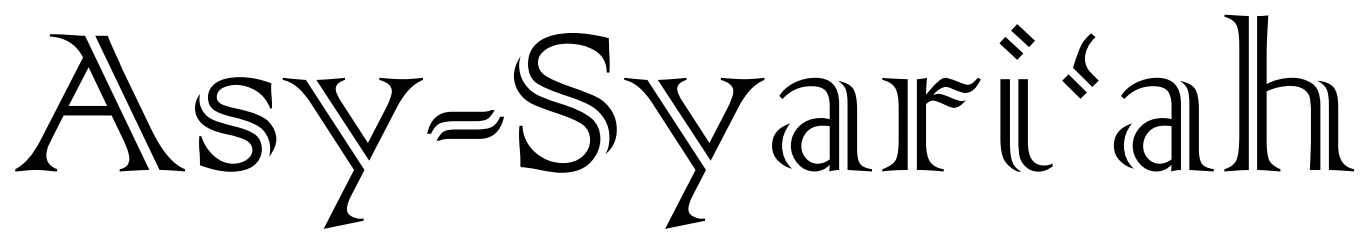

- Islam Nusantara's Perspective on Justice in Polygamy

Beni Ahmad Saebani

- Konstruksi Wakaf Secara Fikih

$(17-30)$ Jaenudin

- Pendekatan Maqashid Syari'ah dalam Praktik Pembiayaan di Koperasi Peternak Sapi Bandung Utara (KPSBU) Lembang Ade Iskandar Nasution

- Kaidah-Kaidah Islam Menjawab Permasalahan Sosial dan Ekonomi Umat

Neneng Hasanah dan Hamzah

- Inovasi Penyaluran Dana Zakat Pada Program Pemberdayaan di Lembaga Amil Zakat

Iw an Setiawan

- Perspektif Siyasah Dusturiyah atas Hak Politik Perempuan dalam Musrembang Kota Bogor

Erma Yulianis

- $\quad$ SBSN PBS, dan SUKRI sebagai Instrumen Pemerintah dalam

Pembiayaan APBN dan Investasi Masyarakat

Suteja Wira Dana Kusuma \& Nisa Dely Amalia

- Partisipasi Politik Kaum Perempuan berdasarkan Pandangan

Fatima Mernissi dan Yusuf Qardhawi

Gayatri Belina Jourdy

FACULTY OF SHARIA AND LAW

STATE ISLAMIC UNIVERSITY SUNAN GUNUNG DJATI BANDUNG-INDONESIA IN COLLABORATION WITH ASOSIASI SARJANA SYARIAH INDONESIA 


\section{Asy-Syari'ah}

\section{Volume 21, Number 1, 2019}

\section{EDITOR-IN-CHIEF}

Ine Fauzia

\section{EDITORIAL BOARD}

Sofyan al-Hakim, UIN Sunan Gunung Djati Bandung, Indonesia Deni Kamaludin Yusup, UIN Sunan Gunung Djati Bandung, Indonesia Meria Utama, Fakultas Hukum Univrsitas Sriwijaya, Indonesia Dewi Mayaningsih, UIN Sunan Gunung Djati Bandung, Indonesia Andrey Sujatmiko, Fakultas Hukum Universitas Trisakti, Jakarta, Indonesia Hetty Hassanah, Universitas Komputer Indonesia, Indonesia

\section{PEER-REVIEWERS}

Muhammad Irfan Helmy, IAIN Salatiga, Semarang, Indonesia Ahmad Ali Nurdin, UIN Sunan Gunung Djati Bandung Tajul Arifin, UIN Sunan Gunun Djati Bandung, Indonesia Mohamad Anton Athoillah, UIN Sunan Gunung Djati Bandung, Indonesia Mrs. Renny Supriyatni, Universitas Padjadjaran, Indonesia Ahmad Tholabi Karlie, UIN Syarif Hidayatullah Jakarta, Indonesia Ija Suntana, UIN Sunan Gunung Djati Bandung, Indonesia Zezen Zaenal Mutaqin, University of California, Los Angeles, United States Ahmad Fathonih, UIN Sunan Gunung Djati Bandung, Indonesia Rahman Syamsuddin, Universitas Islam Negeri Alauddin Makassar, Indonesia

\section{PROOFREADER/DESIGN COVER}

Nanang Sungkawa

\section{LAYOUT EDITOR}

Opik Rozikin

Asy-Syari' ah has been accredited based on the determination of Director General of Research and Development Strengthening, Ministry of Research, Technology and Higher Education of Republic of Indonesia, No. 14/E/KPT/2019 (valid until 2023). 


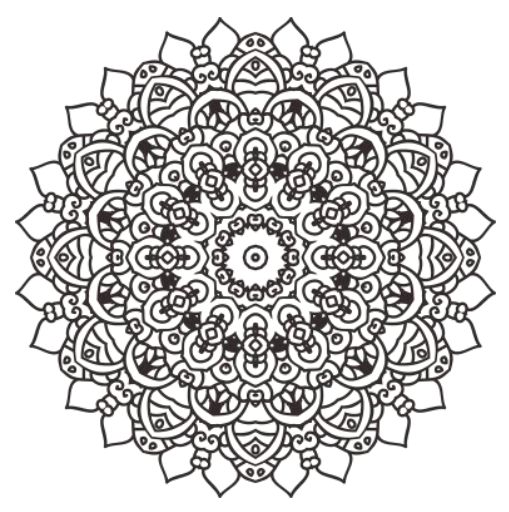

\title{
PENDEKATAN MAQASHID AL-SYARI'AH DALAM PRAKTIK PEMBIAYAAN DI KOPERASI PETERNAK SAPI BANDUNG UTARA (KPSBU) LEMBANG
}

\author{
Ade Iskandar Nasution \\ STIBANKS Al-Masoem \\ Email : adected_me@yahoo.com
}

\begin{abstract}
The chairman of KPSBU took a solution in Annual Member Meeting to eliminate interest on their loan product in order to reduce bad loans and complies the concept of sharia cooperation. This research analyzed whether the maqâshid syarîa has been applied and become a solution to their problems. With descriptive-analytic methods, this research comes to the conclusions that KPSBU Lembang has been implements the maqâshid syarîah with dharûrriyat, hajiyat and tahsiniyat principles. Through the maqâshid syarîah implementation on financing/loan products, customers receive waivers since there is no loan interest, but the customer/member payment is based on profit sharing from the milk sale.
\end{abstract}

Keywords: maqashid syariah, mudharabah, cooperative products 
Abstrak: Ketua Koperasi Peternak Sapi Bandung Utara (KPSBU) Lembang mengambil solusi dalam Rapat Anggota Tahunan (RAT) untuk menghilangkan bunga pada produk pinjaman dengan harapan dapat menekan tingkat kredit macet, sejalan dengan konsep koperasi secara syari'ah. Penelitian ini mencoba untuk menganalisis apakah nilai-nilai maqâshid al-syarîah telah diterapkan dengan baik dan menjadi solusi bagi masalah yang dihadapi. Dengan metode deskriptif analitis, penelitian ini menunjukkan kesimpulan bahwa KPSBU Lembang sudah menerapkan maqâshid al-syarî́ah dalam prinsip dharrîriyat, hajiyat dan tahsiniyat. Melalui penerapan maqâshid al-syarî́ah pada produk pembiayaan/ pinjaman, nasabah memperoleh keringanan. Karena tidak dikenakan bunga atas pinjaman, melainkan bagi hasil berdasarkan hasil penjualan susu dari nasabah kepada koperasi.

Kata-kata Kunci: maqashid syariah, mudharabah, produk koperasi 
Ade Iskandar Nasution, Pendekatan Magashid Syari'ah dalam Praktik Pembiayaan Koperasi...| 33

\section{Pendahuluan}

Koperasi adalah suatu perkumpulan yang beranggotakan orang perorang atau badan hukum, yang memberikan kebebasan kepada anggota untuk masuk dan keluar, dengan bekerjasama secara kekeluargaan menjalankan usaha untuk mempertinggi kesejahteraan jasmaniah para anggotanya. ${ }^{1}$

Koperasi Peternak Sapi Bandung Utara (KPSBU) Lembang yang terletak di Lembang Kabupaten Bandung merupakan koperasi simpan pinjam dengan 4.500 anggota. Dari jumlah keanggotaan tersebut, pendapatan koperasi dalam periode waktu lima tahun dapat dilihat sebagai berikut :

Tabel 1.1

\section{Tingkat PendapatanKoperasiPeternakSapi Bandung Utara Lembang}

\begin{tabular}{ccc}
\hline Tahun & Jumlah Pendapatan (Rp.) & Presentase (\%) \\
\hline 2013 & 268.452 .670 .367 & 0 \\
\hline 2014 & 319.910 .009 .635 & 19,17 \\
\hline 2015 & 389.769 .464 .423 & 18,08 \\
\hline 2016 & 403.269 .913 .245 & 3,46 \\
\hline 2017 & 416.237 .209 .258 & 3,22 \\
\hline
\end{tabular}

Sumber: Koperasi Peternak Sapi Bandung Utara Lembang

Berdasarkan tabel tersebut, jumlah pendapatan koperasi terus mengalami peningkatan, namun dengan prosentase peningkatan yang menurun. Secara ideal dengan jumlah pendapatan yang meningkat, maka pengelolaan koperasi berjalan dengan baik. Namun pada kenyataannya terjadi kredit macet pada produk pinjaman. Ketua koperasi mengambil solusi dalam RAT (Rapat Anggota Tahunan) untuk menghilangkan bunga pada produk pinjaman tersebut dengan harapan dapat menekan tingkat kredit macet.

Dengan penerapan peraturan pengembalian pinjaman tanpa bunga, maka hal ini sejalan dengan konsep koperasi secara syari'ah. Koperasi secara syari'ah menggunakan akad syirkah mufawadhah dimana kedua pihak bekerjasama dengan memberikan dan mengelola modal, demikian juga keuntungan yang diperoleh dibagi secara sama besar bagi kedua pihak tersebut. Koperasi secara syari'ah perlu memenuhi nilai-nilai maqâshid al-syarîah. ${ }^{2}$ Melalui penelitian ini akan dilakukan analisis apakah dengan menerapkan nilai-nilai maqâshid al-syarîah dapat menjadi solusi bagi masalah yang dihadapi.

Berdasarkan penelitian yang dilakukan oleh Zainil Gulham diperoleh kesimpulan bahwa koperasi mengandung nilai kebersamaan, gotong royong dan kesejahteraan bersama. Koperasi syari'ah dapat menjadi pilar pembangunan ekonomi dengan merujuk kepada lima aspek maqâshid al-syarîah. ${ }^{3}$

\footnotetext{
${ }^{1}$ Arifin Sitio dan Tamba Halomoan, Koperasi : Teori dan Praktik (Jakarta: Erlangga, 2001).

2 Buchori N. S., Koperasi Syariah (Sidoarjo: Mashun, 2009).

3 Zainil Gulham, "Impelementasi Maqashid Syari'ah dalam Koperasi Syari'ah," Jurnal Iqtishoduna
} Vol.7, no. 1(2016): hlm. go. 
Tujuan dari penelitian ini adalah untuk mengetahui sejauhmana penerapan maqâshid al-syarî́ah di KPSBU Lembang sehingga dapat diketahui apakah dengan penerapan maqâshid al-syarîah dapat menjadi solusi bagi permasalaan yang dihadapi oleh koperasi.

Secara teori, Imam al-Syâtibi menjelaskan bahwa setiap syari'at yang telah ditetapkan oleh Allah adalah untuk kemaslahatan dan menghindari kemadharatan. Selanjutnya Imam Al-Syâtibi mengklasifikasikan maqâshid al-syarî'ah ke dalam menjaga dharrûriyat (primer), hajiyat (sekunder) dan tahsiniyat (tersier). ${ }^{4}$

Dalam penelitian yang dilakukan oleh Sandy Rizki diperoleh kesimpulan bahwa lahirnya bank syari'ah ditujukan untuk mencapai dan mewujudkan kesejahteraan masyarakat, dengan maqâshid al-syarî́ah sebagai pilar dalam pengembangan dan operasional yang dilakukan oleh perbankan syari'ah. ${ }^{5}$

Dengan demikian diduga bahwa jika KPSBPU Lembang menerapkan maqâshid al-syarîa $h$ dalam operasionalnya, koperasi akan dapat mencapai tujuannya yang sejalan dengan prinsip-prinsip syari'ah.

\section{Metode Penelitian}

Metode penelitian yang digunakan adalah metode penelitian deskriptif analitis kualitatif, karena merupakan sebuah metode penelitian yang digunakan untuk mengungkapkan permasalahan dalam kehidupan kerja organisasi pemerintah, swasta, kemasyarakatan, kepemudaan, perempuan, olah raga, seni dan budaya, dan lain-lain sehingga dapat dijadikan suatu kebijakan untuk dilaksanakan demi kesejahteraan bersama. Menurut Sugiyono, "Masalah dalam penelitian kualitatif bersifat sementara, tentative dan akan berkembang atau berganti setelah peneliti berada di lapangan." ${ }^{6}$

Adapun pengumpulan data dilakukan adalah sebagai berikut: dengan metode studi pustaka, mengenai buku-buku atau referensi yang terkait dengan maqâshid al-syarî́ah dan koperasi; Observasi yang dilakukan di KPSBU Lembang; Wawancara yang dilakukan kepada anggota, pengelola dan masyarakat sekitar KPSBU Lembang; dan Triangulasi, teknik pengumpulan data yang bersifat menggabungkan berbagai teknik pengumpulan data dengan sumber data yang telah ada.

\section{Hasil Penelitian dan Pembahasan}

Salah satu tujuan dari hukum Islam adalah terwujudnya kemaslahatan bagi masyarakat. Bentuk kemaslahatan tercermin melalui maqâshid al-syarî́ah. Imam al-Syâtibi dalam buku yang berjudul al-Muwafaat menjelaskan maqâshid al-syarî́ah sebagai tujuan

\footnotetext{
${ }^{4}$ Asy-Syatibi, al-Muwfâqât fîUsûl asy-Syarî'ah (Beirut: Daral- Kutub alllmiyyah, 1997).

5 Rizki S, "Aplikasi Maqasid Syariah dalam Bidang Perbankan Syariah," Jurnal Amwaluna Vol.1, no. 2 (2017).

6 Sugiyono, Metode Penelitian Pendidikan Pendekatan Kuantitatif, Kualitatif dan R\&D (Bandung: Alfabeta, 2010).
} 
Ade Iskandar Nasution, Pendekatan Magashid Syari'ah dalam Praktik Pembiayaan Koperasi...|35 dan hikmah dari suatupermasalahan atau kegiatan yang dilakukan. ${ }^{7}$ Berdasarkan ulama Ushul Fiqh, maqâshid al-syarîa h terbahagi ke dalam Dharûrriyat, Hajiyat dan Tahsiniyat.

Pendapat Yusuf Muhammad dalam buku Maqâshid al-syarî́ah 'Inda Ibn Taimiyah menjelaskan "Dharuriyat dapat dibedakan menjadi menjaga agama, menjaga jiwa, menjaga akal, menjaga keturunan dan menjaga harta." ${ }^{8}$

Penjelasan mengenai penerapan maqâshid al-syarî́ah di koperasi KPSBU Lembang adalah sebagai berikut:

\section{Dharurriyat}

Dharurriyat merupakan kebutuhan primer bagi manusia dalam hal menciptakan kemaslahatan agama dan dunia. Dharurriyat terbagi ke dalam lima aspek (mafsadah) yakni perlindungan terhadap agama ( $h i f d z u$ ad-diin), perlindungan terhadap jiwa ( $h i f d z u$ an-nafs), perlindungan terhadap akal (hifdzu al-'aql), perlindungan terhadap keturunan ( hifdzu an-nasl) dan perlindungan terhadap harta ( ifdzual-maal). ${ }^{9}$

Perlindungan terhadap agama, berlandaskan pada tujuan diciptakannya manusia adalah untuk melakukan ibadah. Hal ini berdasarkan pada Firman Allah SWT sebagai berikut:

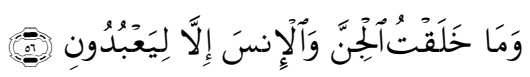

Dan aku tidak menciptakan jin dan manusia melainkan supaya mereka mengabdi kepada-Ku. (Adz-Dzâriyât: 56)

Peran Koperasi KPSBU Lembang dalam menerapkan prinsip perlindungan terhadap agama (hifdzu ad-diin) yaitu mewujudkan kesempurnaan ibadah manusia dalam hal ini adalah menerima titipan tabungan dari nasabah. Tabungan/ simpanan nasabah memang tidak secara spesifik ditujukan untuk menjaga agama. Namun demikian nasabah dapat menggunakan tabungan tersebut untuk tujuan tertentu, misalnya menabung untuk menunaikan ibadah umrah, haji dan kegiatan positif lainnya yang bernilai sebagai ibadah.

Prinsip kedua adalah perlindungan terhadap jiwa (hifdzu an-nafs), yaitu dalam aspek memberikan perlindungan dari hal-hal yang mengganggu jiwa dan fisik seseorang. Dalam hal ini KPSBU Lembang menerima titipan tabungan dari nasabah koperasi. Tabungan ini dapat ditarik kembali oleh nasabah ketika dibutuhkan untuk memenuhi kebutuhannya atau ketika terjadi hal buruk yang menimpa diri nasabah.

Prinsip ketiga adalah perlindungan terhadap akal ( $h i f d z u$ al-'aql), dengan didasarkan pada ayat berikut:

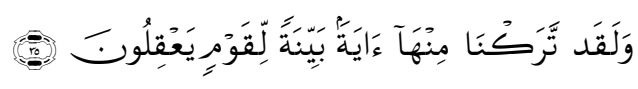

\footnotetext{
7 Ismail N, Maqashid Syariah dalam Ekonomi Islam (Yogyakarta: Smart WR, 2014).

${ }^{8}$ Al-Badawiy D.Y.(n.d), Maqahid al-Syariah 'Inda Ibn Taimiyah (Yordania: Dar al-Nafais Al-Syatibi, 1997).

9 Syatibi, al-Muwfâqâtfî Usûl asy-Syarî'ah.
} 
Dan Sesungguhnya Kami tinggalkan daripadanya satu tanda yang nyata bagi orang-orang yang berakal. (Al-'Ankabut: 35)

Manusia memiliki akal yang harus dijaga fungsinya untuk mewujudkan kemaslahatan bagi dirinya dan lingkungan sekitarnya. Peran KPSBU Lembang dalam menerapkan maqâshid al-syarî́a h pada prinsip menjaga akal adalah dengan memberikan pembiayaan/ pinjaman bagi nasabah untuk kebutuhan konsumtif seperti memenuhi kebutuhan pendidikan bagi nasabah dan keluarganya. Mengenyam pendidikan adalah salah satu cara untuk menjaga fungsi dan kesehatan akal manusia. Dengan demikian melalui produk pembiayaan/ pinjaman KPSBU Lembang menerapkan maqâshid al-syarî́ah.

Prinsip keempat adalah perlindungan terhadap keturunan (hifdzu an-nasl). Dengan adanya produk tabungan/ simpanan di KPSBU Lembang memberikan kesempatan bagi nasabah untuk memiliki simpanan berupa uang yang dapat digunakann untuk kebutuhan nasabah di waktu yang akan datang. Selain produk simpanan, KPSBU Lembang juga memberikan produk pembiayaan/ pinjaman yang dapat digunakan sebagai modal usaha bagi nasabah. Sehingga nasabah dapat membiayai kebutuhan keluarga. Dengan usaha dan penghasilan yang berkecukupan, diharapkan kehidupan ekonomi nasabah dapat terjamin. Hal ini sebagaimana terjemahan dalam Firman Allah SWT sebagai berikut :

"Dan hendaklah takut kepada Allah orang-orang yang seandainya meninggalkan dibelakang mereka anak-anak yang lemah, yang mereka khawatir terhadap (kesejahteraan) mereka. oleh sebab itu hendaklah mereka bertakwa kepada Allah dan hendaklah mereka mengucapkan Perkataan yang benar". (Al-Nisaâ : 9)

Prinsip kelima adalah perlindungan terhadap harta (hifdzu al-maal). Perlindungan harta dapat dilihat melalui aspek pengelolaan dana. Perlindungan harta dapat dilakukan melalui memiliki simpanan/tabungan. Tabungan/ simpanan nasabah dikelola oleh koperasi. Pada setiap akhir tahun nasabah berhak memperoleh bagian/ sisa hasil usaha (SHU) yang diperoleh oleh KPSBU Lembang.

\section{Hajiyat}

Maqâshid al-syarîah kedua adalah hajiyat, yang merupakan kebutuhan sekunder. Dimana jika suatu kebutuhan tidak tercukupi, tidak akan menyebabkan madharat bagi manusia. KPSBU Lembang menerapkan prinsip hajiyat ini melalui pelaksanaan pembiayaan/pinjaman modal usaha yang menggunakan akad bagi hasil.

Mayoritas nasabah koperasi merupakan peternak susu, di mana nasabah dapat meminjam modal usaha dari koperasi kemudian mengembalikan pinjaman dengan cara angsuran. Angsuran dibayarkan dengan cara nasabah menjual susu ke koperasi dan hasil penjualan susu tersebut digunakan untuk membayar angsuran nasabah.

\section{Tahsiniyat}

Tahsiniyat merupakan tingkat kebutuhan pelangkap, merupakan bagian dari adat 
Ade Iskandar Nasution, Pendekatan Magashid Syari'ah dalam Praktik Pembiayaan Koperasi...| 37 masyarakat yang berpegang pada nilai moral dan akhlak. ${ }^{10}$ Penerapan maqâshid al-syarîah pada prinsip tahsiniyat yang terdapat di KPSBU Lembang adalah tidak menerima pembiayaan/pemberian pinjaman untuk hal-hal yang mengandung nilai maksiat atau modal usaha yang menyalahi ketentuan syari'at.

\section{Kesimpulan}

Berdasarkan hasil pembahasan, maka diperoleh kesimpulan sebagai berikut : KPSBU Lembang sudah menerapkan pendekatan maqâshid al-syarî́ah dalam prinsip dharurriyat, hajiyat dan tahsiniyat. Melalui penerapan maqâshid al-syarîah pada produk pembiayaan/pinjaman, nasabah memperoleh keringanan. Karena tidak dikenakan bunga atas pinjaman, melainkan bagi hasil berdasarkan hasil penjualan susu dari nasabah kepada koperasi.

\section{DAFTAR PUSTAKA}

D.Y.(n.d), Al-Badawiy. Maqahid al-Syariah 'Inda Ibn Taimiyah. Yordania: Dar al-Nafais Al-Syâtibi, 1997.

Gulham, Zainil. "Impelementasi Maqashid Syari'ah dalam Koperasi Syari'ah." Jurnal Iqtishoduna Vol.7, no. 1 (2016).

N, Ismail. Maqashid Syariah dalam Ekonomi Islam. Yogyakarta: Smart WR, 2014.

N. S., Buchori. KoperasiSyariah. Sidoarjo: Mashun, 2009.

S, Rizki. "Aplikasi Maqasid Syariah dalam Bidang Perbankan Syariah." Jurnal Amwaluna Vol.1, no. 2 (2017).

Sitio, Arifin, dan Tamba Halomoan. Koperasi : Teoridan Praktik. Jakarta: Erlangga, 2001.

Sugiyono. Metode Penelitian Pendidikan Pendekatan Kuantitatif, Kualitatif dan R\&D. Bandung: Alfabeta, 2010.

Syatibi, Asy-. al-MuwfâqâtfîUsûl asy-Syarîah. Beirut: Daral-Kutub alllmiyyah, 1997. 
38 |Asy-Syari'ah Vol. 21 No. 1, Juli 2019 
Asy-Syari'ah (P-ISSN : 2086-9029 E-ISSN: 2654-5675) is a periodical scientific journal that publishes various results of studies and research, literature review, and other scientific works whose scope covers the field of Islamic law/sharia, law and society in monodisciplinary, interdisciplinary, and multidisciplinary manners. The journal aims to expand and create innovative concepts, theories, paradigms, perspectives and methodologies in the above said scope. The Journal is published twice a year (june and december) by Faculty of Shariah and Law, Sunan Gunung Djati State Islamic University Bandung in collaboration with Asosiasi Sarjana Syariah Indonesia (ASSYI).

\section{EDITORIAL OFFICE:}

Fakultas Syariah dan Hukum UIN Sunan Gunung Djati Bandung Jl. Raya A.H. Nasution No. 105 Cibiru Kota Bandung, 40614

Tlp/Fax: +022-7802278 Faks. 022-7802278

Website http://journal.uinsgd.ac.id/index.php/asy-syariah/index

E-mail: Jurnalasy-syariah@uinsgd.ac.id 